\title{
An exact model for airline flight network optimization based on transport momentum and aircraft load
}

\section{factor}

\author{
Daniel Jorge Caetano ${ }^{1}$, Nicolau Dionísio Fares Gualda ${ }^{2}$ \\ ${ }^{1}$ Escola Politécnica da Universidade de São Paulo, djcaetano@usp.br \\ 2Escola Politécnica da Universidade de São Paulo, ngualda@usp.br
}

\section{Recebido:}

23 de maio de 2017

Aceito para publicação:

03 de setembro de 2017

Publicado:

30 de dezembro de 2017

Editor de área:

Li Weigang

\section{Keywords:}

Air transportation, Schedule generation,

Fleet assignment,

Linear programming.

\section{Palavras-chaves:}

Transporte aéreo,

Programação de voos,

Alocação de frotas,

Programação linear.

DOI:10.14295/transportes.v25i4.1383

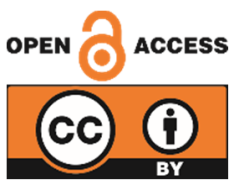

\begin{abstract}
The problem of airline flight network optimization can be split into subproblems such as Schedule Generation (SG) and Fleet Assignment (FA), solved in consecutive steps or in an integrated way, usually based on monetary costs and revenue forecasts. A linear programming model to solve SG and FA in an integrated way is presented, but with an alternative approach based on transport momentum and aircraft load factor. This alternative approach relies on demand forecast and allows obtaining solutions considering minimum average load factors. Results of the proposed model applications to instances of a regional Brazilian airline are presented. The comparison of the schedules generated by the proposed approach against those obtained by applying a model based on monetary costs and revenue forecasts demonstrates the validity of this alternative approach for airlines network planning.
\end{abstract}

\section{RESUMO}

O problema da otimização da malha de uma empresa aérea pode ser dividido em subproblemas como a Programação de Voos (PV) e a Alocação de Frotas (AF), resolvidos em etapas ou de maneira integrada, normalmente com base em previsões de custos e receitas. Um modelo de programação linear é apresentado para resolver a PV e a AF de maneira integrada, porém adotando uma abordagem alternativa, baseada no momento de transporte e na taxa de ocupação das aeronaves. Tal abordagem depende apenas de previsões de demanda e permite considerar taxas mínimas de ocupação das aeronaves. São apresentados resultados da aplicação do modelo a instâncias associadas a uma empresa áerea regional brasileira. A comparação das programações de voo obtidas pela abordagem proposta em relação às obtidas por um modelo baseado em custos e receitas demonstra a validade dessa abordagem alternativa para o planejamento das malhas das empresas aéreas.

\section{INTRODUCTION}

The main goal of airlines strategic planning is the increase in efficiency and profitability. Determining the optimal flight network is an important component of this strategic plan, which comprehends what markets and how many flights to serve and which resources - aircrafts and crew - to allocate to each flight (GÜRKAN et al., 2016; SHERALI et al., 2013).

A single model to determine the optimal flight network, albeit desirable, generally leads to large-scale problems of the NP-Hard class (HANE et al. 1995; KLABJAN, 2004). It is a common practice to divide the problem into smaller problems such as Schedule Generation, Fleet Assignment and Crew Assignment, solved in consecutive steps, seeking to compute a solution at feasible times (RABETANETY, 2006). This practice, however, does not guarantee the optimal global solution.

No matter how many steps are used to solve the problem, the usual approach relies on objective 
functions based on monetary costs and revenue forecasts, which, in turn, are based on passenger forecasts and can thus suffer significant fluctuations when changes are made to the flight network.

The objective of this paper is to present an alternative objective function that allows solving the integrated Schedule Generation and Fleet Assignment problem relying only on demand forecasts, avoiding the need of revenues and/or costs forecasts.

The objective function proposed encompasses variables based on transport momentum as a proxy of operational costs and revenues. Moreover, the model proposed allows imposing a minimum overall load factor for solving the problem.

The paper sequence begins with a brief review of the airline operational planning concepts, including details on the approach with the objective function related to costs and/or revenues. This is followed by a presentation of the alternative objective function proposed. Finally, the results of the model application to instances of a regional Brazilian airline are presented and compared to results from the revenuerelated model, along with a brief analysis concerning the imposition of a minimum overall load factor.

\section{AIRLINE OPERATIONAL PLANNING}

Airlines operational planning encompasses the definition of the flights to be offered, of the aircraft to be used for each flight, and of the crew to perform each of these flights. These decisions are usually associated to results of three interrelated processes that, in turn, may be divided into smaller subproblems, usually solved sequentialy, as shown in Figure 1.

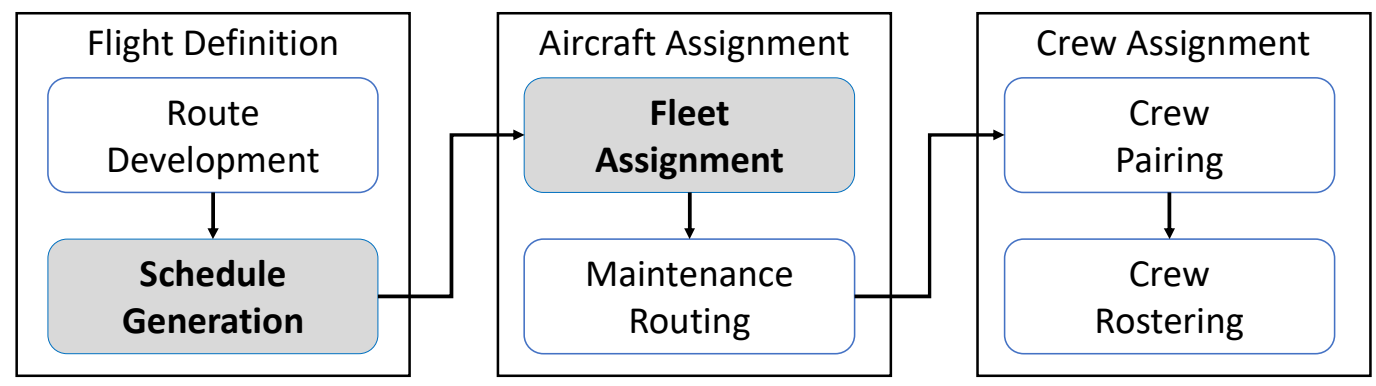

Figure 1: Airline operational planning stages (Based on: CAETANO \& GUALDA, 2010)

Flight definition is the first process, which defines the flight schedule. This process can be divided into two subproblems: Route Development and Schedule Generation. In Route Development, the demands between city pairs are identified and thus potential flights between airport pairs are defined. It is crucial to address airports restrictions at this step - such as operating time restrictions -, to prevent the inclusion of operationally impossible flights in the solution. In Schedule Generation, the flights that will actualy be on flight schedule are selected. (KLABJAN, 2004; RABETANETY, 2006).

Aircraft Assignment, the second process, defines the sequence of scheduled flights each aircraft will perform. This process can also be divided into two subproblems: Fleet Assignment and Maintenance Routing. In Fleet Assignment, the best aircraft type is assigned to each scheduled flight, aiming at profit maximization - usually related to aircraft capacity and demand forecasts. In Maintenance Routing, the operational restrictions of each aircraft - such as maintenance schedule - are considered to define its exact flight sequence. The schedule of each aircraft shall define where and when each one will be out of duty, in order to be serviced (BARNHART et al. 2003; KLABJAN, 2004, SHERALI et al., 2013).

Crew Assignment, the third process, defines the crew members that will be assigned to each flight. This process can be divided into two subproblems also: Crew Pairing and Crew Rostering. In Crew Pairing, flights are grouped into sequences called pairings, which must respect labor laws and technical criteria. In Crew Rostering, the pairings - and, thus, the flights - are assigned to the crew members (BARNHART et al., 2003; GOMES, 2014; GOMES \& GUALDA, 2011; GOMES \& GUALDA, 2015; KLABJAN, 2004; RABETANETY et al., 2006). 
The competition among airlines and the complexity of aircraft, crew and passenger management lead to large-scale models for airlines operational planning. Even when each planning subproblem is addressed by a specific model, it is usually also of the NP-hard class (HANE et al., 1995). Seeking global optimization, models are addressed to solve two or more subproblems simultaneously, increasing the computational complexity (KLABJAN, 2004; SHERALI et al. 2013; RABETANETY et al., 2006). Consequently, heuristics and metaheuristics approaches have been proposed, such as the one by Caetano and Gualda (2011), addressed to solve the Schedule Generation and Fleet Assignment integrated problem with an Ant Colony Metaheuristic approach, and the ones by Gomes and Gualda (2011; 2015), for solving the integrated Airline Crew Assignment problem.

The most common approach to solve the airline planning process is to divide it into several steps, as mentioned earlier. Each step is optimized based on different objective functions: the Flight Definition step is usually solved using marketing, revenue, aircraft availability and other operational restrictions as optimization criteria (KLABJAN, 2004; RABETANETY et al., 2006); the Aircraft Assignment step usually involves mainly the consideration of costs and revenues to maximize profitability (HANE et al., 2004; KLABJAN, 2004; SHERALI et al., 2006); and, finally, the Crew Assignment step is based on the availability of human resources, legal matters and costs (BARNHART et al., 2003; GOMES, 2014; GOMES \& GUALDA, 2011; GOMES \& GUALDA, 2015; KLABJAN, 2004).

Notice that costs and revenues are directly or indirectly related to each step of the airline planning process. This is the reason why models proposed to solve more than one step in an integrated way usually rely on costs and/or revenues as the main parameters of their objective functions. Other characteristics are usually addressed by model constraints (LOHATEPANONT \& BARNHART, 2004; SALAZAR-GONZÁLEZ, 2014).

Among all the airline planning steps described previously, Schedule Generation and Fleet Assignment problems are considered the most important ones related to the airline profitability and service level and, therefore, good candidates to be solved in an integrated way (DONG et al., 2016). These problems have been solved in an integrated way by Caetano \& Gualda $(2010 ; 2011)$ using a model that encompasses some activities that can be considered part of Route Development - consideration of alternative flights to be offered - and some that can be considered part of Maintenance Routing - such as the regular maintenance time after each flight. It is relevant to remark that this model does not include all the aspects covered by Route Development and Maintenance Routing subproblems.

The model proposed by Caetano \& Gualda (2011) is based on previous models by Berge \& Hopperstad (1993), Sherali et al. (2006) and Lohatepanont \& Barnhart (2004). It is structured as a space-time network, including the elements shown in Figure 2. Since the arrival slot time constraints are based on the flight arrival time, the space-time network includes explicit arcs for maintenance after flight - during which the aircraft is unavailable - so that the flight arcs ends at the correct time, even if the aircraft is unavailable for a longer period of time.

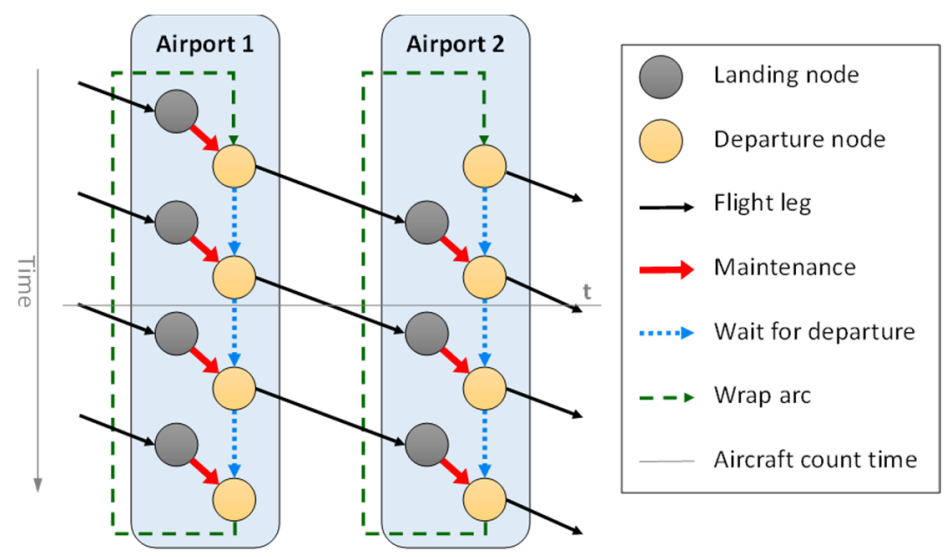

Figure 2: Space-time network (Based on CAETANO \& GUALDA, 2011) 
Note that if one fleet cannot execute a direct flight between two airports - because of its range limitation -, the network for that fleet shall not include the arcs representing that flight - different fleet networks may include different sets of arcs. The same rationale applies when one aircraft cannot operate at an airport: no flight arc should connect that fleet to the restricted airport.

The model based on such space-time network is presented below (Caetano \& Gualda, 2011):

$$
[\min ] \sum_{(i, j) \in L f}\left[\left(\sum_{f \in F} R_{i j} \cdot C^{f} \cdot x_{i j}^{f}\right)-R_{i j} \cdot p a_{i j}+R_{i j} \cdot\left(d_{i j}-p a_{i j}\right)\right]
$$

Subject to:

Binaries:

$$
\begin{gathered}
\sum_{f \in F} x_{i j}^{f} \leq 1 \quad \forall(i, j) \in L f_{m}, \forall m \in M \\
\sum_{o \mid(o, k) \in L} x_{o k}^{f}-\sum_{d \mid(k, d) \in L} x_{k d}^{f}=0 \quad \forall k \in N_{f}, \forall f \in F \\
\sum_{(i, j) \in L t} x_{i j}^{f} \leq A_{f} \quad \forall f \in F \\
\sum_{f \in F} \sum_{j \mid(i, j) \in L_{f}} x_{i j}^{f} \leq 1 \quad \forall i \in N r d \\
\sum_{f \in F} \sum_{i \mid(i, j) \in L_{f}} x_{i j}^{f} \leq 1 \quad \forall j \in N r a \\
\sum_{f \in F} C^{f} \cdot x_{i j}^{f}-p a_{i j} \geq 0 \quad \forall(i, j) \in L f \\
d_{i j}-p a_{i j} \geq 0 \quad \forall(i, j) \in L f \\
\sum_{(i, j) \in L f_{m}} d_{i j}-D_{m}=0 \quad \forall m \in M
\end{gathered}
$$

Integers:

$$
x_{i j}^{f} \in\{0,1\} \quad \forall(i, j) \in L f_{m}, \forall m \in M
$$

$$
\begin{array}{cl}
x_{i j}^{f} \geq 0 \quad \forall(i, j) & \in L \backslash L f_{m}, \forall m \in M \\
d_{i j} \geq 0 & \forall(i, j) \in L f \\
p a_{i j} \geq 0 & \forall(i, j) \in L f
\end{array}
$$

Where: $M$ : set of all markets, indexed by $m$; each market defines a demand and a time window that limits which flights can serve this demand.

$N_{f}$ : set of all nodes for aircraft $f$, indexed by $i, j, o, d$ or $k$, representing an airport at a specific time.

$N r d$ : set of nodes with departure restrictions.

Nra: set of nodes with landing restrictions.

$F$ : set of all types of aircraft, indexed by $f$.

$L$ : set of arcs that represent the movement of aircraft, minimum maintenance after flight turn-around time -, waiting on the ground or wrap, indexed by $(i, j), i$ is the source node and $j$ is the destination node of the movement.

$L f$ : set of arcs that represent flight movements.

$L f_{m}$ : set of arcs representing flights assigned to a market $m$.

$L_{\mathrm{t}}$ : set of arcs whose origin time is equal to or less than $t$ and destination time is after $t$. Time $t$ is set to a valid time according to the problem.

$D_{m}$ : unrestricted passenger demand for market $m$.

$C f$ : number of seats of type $f$ aircraft.

$R_{i j}$ : unitary revenue for a passenger on the flight from node $i$ to node $j$. Since $(i, j)$ represent a specific flight - including day and time - each flight may be associated with a unitary revenue.

$A_{f}$ number of aircraft of type $f$ available.

$x_{i j}$ : number of aircraft of type $f$ flowing through $\operatorname{arc}(i, j)$. 
$d_{i j}$ : number of potential passengers (demand) associated to the flight from node $i$ to node $j$. $p a_{i j}$ : number of passengers associated to the flight from node $i$ to node $j$.

The objective function - Equation 1 - seeks to minimize the sum of lost revenues. The first term represents the difference between maximum revenue for the assigned aircraft and the revenue received from assigned passengers. The second term is associated to the lost revenue due to lost demand.

Equations 2 to 4 represent the usual cover, balance and number of aircraft restrictions (BERGE \& HOPERSTEAD, 1993; SHERALI et al., 2006; HANE et al., 1995).

Equations 5 and 6 represent slot constraints, assuring that only one aircraft will depart or land on those nodes, respectively. Equations 7 to 9 assure that each market demand will be associated to each flight and that the passengers of a flight will never be greater than the associated aircraft capacity.

The variables representing demanded flight arcs are binary, and are specified in equation 10 . All the other arc variables are integers greater than or equal to zero, as stated in Equations 11, 12 and 13.

However, the use of revenues as input data on planning models presents some practical problems. First of all, revenues are not only based on demand - which is estimated - but also on ticket price, which can fluctuate according to the yield management strategy (MAYO, 1999). The former, however, may not exist or even not reflect the optimum for a specific solution - the current airline flights - and, therefore, it may introduce undesired bias in the solution process.

Modifying any model to rely on costs instead of revenues brings another set of problems to discussion. If only operational costs are taken into account, the "optimal" solution may lead to a large passenger spill - passengers not served. The solution would be to force all the demand to be served which is not always a practical approach - or to add a "cost" for each passenger not served. The definition of the latter cost is a problem in itself (KLABJAN, 2004; SHERALI et al., 2006).

These problems are present not only in the model described by equations 1 to 13 . Most recent models presented in the literature to solve this integrated problem - such as the ones by Lohatepanon \& Barnhart (2004), Sherali et. al. (2013), Di Wang et al. (2014) and Salazar-González (2014), and Dong et al. (2016) - rely on estimated fares, revenues and/or costs and, therefore, may include some kind of bias.

Also, when analyzing the whole planning process, the cost of a flight is not only dependent on which aircraft is used for each flight leg, but also on the order in which these legs are covered, on the choice of the crew members in each flight leg, and so on (CAETANO \& GUALDA, 2011; GOMES, 2014; GOMES \& GUALDA, 2011; SHERALI et al., 2006; KLABJAN, 2004). In other words, since the flight cost is also dependent on the model output, it is not desirable to use it as a model input.

\section{ALTERNATIVE OBJECTIVE FUNCTION}

The most common objective of airlines planning is to maximize profit. Therefore, objective functions ignoring costs and revenues are not realistic in most cases. However, parameters that are easier to determine within the planning time may act as cost or revenue proxies and prevent the introduction of biases in the process.

A favorable proxy for the operational cost is the potential transport momentum (seats. miles or seats. kilometers), or PTM, once there is a good correlation between them (SWAN \& ADLER, 2006). Since the demand forecast is a required input parameter for the airline planning process, and since the flight distance can be determined, PTM is readily available at the planning time. Since flight distances and flight times are also correlated, an alternative could be to determine PTM in terms of seats . hours.

For similar reasons, considering a uniform yield management strategy, the effective transport momentum (passengers. miles, passengers. kilometers or passengers. hours), or ETM, may be a favorable proxy for operational revenues.

However, given PTM and ETM as proxies of costs and revenues, the profitability cannot be obtained by simply subtracting PTM from ETM: the result would always be negative. Hence, additional considerations are needed to estimate whether a flight would be profitable or not. 
Analyzing the situation from another perspective, it is possible to consider empty seats on a flight as wasted potential transport momentum, or WPTM. These seats could have generated some revenue, but they have not. Then, WPTM corresponds to the difference between PTM and ETM.

In a maximum coverage model - all flights must be assigned -, the objective function can be simply stated to minimize WPTM. However, if the model defines which flights should be performed - in a schedule generation process, for instance - minimization of WPTM will always lead to an empty schedule there is no penalty for unmet demand and no empty seats are accounted when there are no flights. The solution for this limitation can be achieved by considering the spilled demand as lost revenue, and, likewise, the wasted effective transport momentum, or WETM.

The flight wasted transport momentum, WTM, can be obtained by adding WPTM to WETM, and the objective function could be simply to minimize the sum of the WTM for each flight leg, as presented in Equation 14.

$$
[\text { Min }] \sum_{(i, j) \in L f}\left[\left(P_{T} M_{i j}-\text { ETM }_{i j}\right)+\text { WETM }_{i j}\right]
$$

Minimizing the sum of WPTM and WETM enforces the need to find a balance between empty seats and unmet demand. The formulation, however, implies that not carrying a passenger has the same cost as an empty seat on a specific flight. In other words, there is an implicit assumption that the operational break-even will be met with a 50\% load factor, or LF. This occupation ratio is not realistic in most cases, and probably most airlines would prefer to set a specific break-even load factor, BELF, the occupation ratio that makes a flight attractive, according to their individual expectations.

For a given flight demand, the aircraft type selected has direct impact on the load factor. The opposite is also true: variations in the minimum acceptable load factor will impact the viable aircraft type choices for a specific flight. In practice, the relationship between load factor and aircraft size, associated to demand and flight distance, can be used to forecast aircraft movements in a flight leg (KÖLKER et al., 2016) or an aircraft route. These relationships suggest that flight demand, flight length and load factor should all be considered for selecting which fleet will perform each flight.

As mentioned earlier, a new model constraint could be used to overcome the implicit $50 \%$ BELF. The minimum load factor on a flight, $\delta$, could be limited by the constraint presented in Equation 15.

$$
\left(\frac{p a_{i j}}{\sum_{f \in F} C^{f} \cdot x_{i j}^{f}}-\delta\right) \geq 0
$$

However, the model should allow lower load factors on selected flights once proven that those flights are being used to reposition an aircraft to perform a high-occupancy flight (or flights). Therefore, a better approach would be to allow load factor compensation among flights. The flight length should also be considered, since low occupation ratio on shorter flights is less harmful than on longer flights. Adopting the flight time $T_{i j}$ as a weight, the previous constraint can be rewritten to meet these requirements to limit the minimum time-weighted load factor, TWLF, as show in Equation 16.

$$
\sum_{(i, j) \in L_{f}} T_{i j}\left(\frac{p a_{i j}}{\sum_{f \in F} C^{f} \cdot x_{i j}^{f}}-\delta\right) \geq 0
$$

Unfortunately, this constraint is not linear when the number of passengers per flight, $p a_{i j}$, is a decision variable. Nonetheless, it is possible to achieve BELF control by using cost weights in the objective function while keeping the linear nature of the model: if the cost of an empty seat is the same as the cost of a lost passenger, the BELF will be $50 \%$. On the other hand, if an empty seat costs more than a lost passenger, to perform a flight at $50 \%$ occupation would be more expensive than not performing that flight at all, and BELF will be higher than $50 \%$.

The objective function presented in Equation 17 allows this kind of control through weights $\alpha$ and $\beta$. 


$$
[\mathrm{Min}] \sum_{(i, j) \in L f}\left[\alpha \cdot\left(\mathrm{PTM}_{i j}-\mathrm{ETM}_{i j}\right)+\beta \cdot \text { WETM }_{i j}\right]
$$

To achieve a BELF of $\delta$, the $\alpha / \beta$ ratio should be calculated as presented in Equation 18.

$$
\frac{\alpha}{\beta}=\frac{\delta}{1-\delta}
$$

As an example, if $\alpha=3$ and $\beta=2, \delta$ is $60 \%$. Fixing $\beta$ as 1 would simplify the model, but keeping them both allows the use of integral values in most cases, which may be desirable to avoid rounding errors.

However, note that BELF does not represent the "desired occupation ratio", but the reference average occupation ratio to be accepted by the model as a viable solution. As a direct consequence, if an airline sets this value too high - such as $85 \%$, which is a common occupation ratio target -, several profitable long flights may be eliminated from the schedule due to the need of some low occupation, short repositioning flights.

The alternative model formulation, incorporating the proposed objective function, becomes:

$$
[\min ] \sum_{(i, j) \in L f}\left\{T_{i j} \cdot\left[\alpha .\left(\left(\sum_{f \in F} C^{f} \cdot x_{i j}^{f}\right)-p a_{i j}\right)+\beta \cdot\left(d_{i j}-p a_{i j}\right)\right]\right\}
$$

Subject to:

$$
\begin{aligned}
& \sum_{f \in F} x_{i j}^{f} \leq 1 \quad \forall(i, j) \in L f_{m}, \forall m \in M \\
& \sum_{o \mid(o, k) \in L} x_{o k}^{f}-\sum_{d \mid(k, d) \in L} x_{k d}^{f}=0 \quad \forall k \in N_{f}, \forall f \in F \\
& \sum_{(i, j) \in L t} X_{i j}^{f} \leq A_{f} \quad \forall f \in F \\
& \sum_{f \in F} \sum_{j \mid(i, j) \in L_{f}} x_{i j}^{f} \leq 1 \quad \forall i \in N r d \\
& \sum_{f \in F i \mid(i, j) \in L_{f}} x_{i j}^{f} \leq 1 \quad \forall j \in N r a \\
& \sum_{f \in F} C^{f} \cdot x_{i j}^{f}-p a_{i j} \geq 0 \quad \forall(i, j) \in L f \\
& d_{i j}-p a_{i j} \geq 0 \quad \forall(i, j) \in L f \\
& \sum_{(i, j) \in L f_{m}} d_{i j}-D_{m}=0 \quad \forall m \in M
\end{aligned}
$$

Binaries:

$$
x_{i j}^{f} \in\{0,1\} \quad \forall(i, j) \in L f_{m}, \forall m \in M
$$

Integers:

$$
\begin{gathered}
x_{i j}^{f} \geq 0 \quad \forall(i, j) \in L \backslash L f_{m}, \forall m \in M \\
d_{i j} \geq 0 \quad \forall(i, j) \in L f \\
p a_{i j} \geq 0 \quad \forall(i, j) \in L f
\end{gathered}
$$

The model described by Equations 19 to 31 is very similar to that presented by Equations 1 to 13 . In fact, the only change is the new objective function shown in Equation 19, which is the full form of Equation 17: $P T M_{i j}$ is represented by the flight time $T_{i j}$ multiplied by the capacity of the used aircraft $C^{f} . x_{i j}$; $E T M_{i j}$ is represented by the flight time $T_{i j}$ multiplied by the passengers allocated to that flight $p a_{i j}$; and, finally, $W E T M_{i j}$ is represented by the flight time $T_{i j}$ multiplied by the spilled demand associated to that flight $\left(d_{i j}-p a_{i j}\right)$. 
Since no other constraints were changed, this model can solve the same instances from the model presented by Caetano \& Gualda (2011), allowing for comparing the results provided by both models. The only additional required data is the BELF specification in the form of $\alpha$ and $\beta$ values.

\section{METHODOLOGY}

This study proposes an alternative objetive function to a model previously designed for solving the integrated Schedule Generation and Fleet Assignment problem, which has been applied and tested with instances based on data from a Brazilian regional airline. In order to allow direct comparison of the results, all the characteristics of the original model and instances will be kept:

- The schedule must cover an entire operation week.

- The schedule must be cyclical - the fleet that starts the week at one airport should finish the week at that same airport.

- Flight times will be the average flight time between two airports, the same for all aircrafts.

- Performance differences among aircrafts will not be considered.

- Only direct flights are considered, there are no hubs.

- Any aircraft may perform any flight.

Besides the data provided by the airline, additional data were obtained from public sources - such as the Brazilian Civil Aviation regulatory agency website and annual reports. Since the demand was provided aggregated in the form of annual totals for each origin/destination pair - and the only serving airline between those airports was the one considered in this study -, the demand was estimated in two different ways: an average per flight demand - based on the number of flights between each origin/destination per week - and an average per day period - morning and afternoon. Since demand should always be an integer, the average demand for each flight or period was rounded.

Since the model is not designed to create new flights by itself, the original proposed scheduled flights are complemented with additional alternative flights, allowing the possibility of alternative repositioning flights. The additional flights are created as the "earliest" flight possible at the end of each proposed flight and the "latest" possible flight arriving just before each flight. Since the airline does not perform flights between some pairs of airports, the mentioned network expansion process is performed twice to assure that any aircraft may be repositioned to any other airport.

Initially, the model incorporating the alternative objective function will be used to solve some instances already solved by the original model. The results will be compared in terms of selected flights, demand met, average load factor and weighted load factor for two different BELFs: one very low - 50\% - and a more usual one $-75 \%$. Since no other changes were introduced in the model besides the objective function, a comparison of the results may be used to validate the model: if the new objective function works as expected, and provided that the revenues are optimally defined for the revenue-based model, the same instances solved by both models, with usual and alternative objective functions, should lead to similar flight schedules.

Once the model has been validated, several instances will be tested, with different BELF values and the results will be compared in terms of selected flights, demand met, average load factor and weighted load factor.

\section{APPLICATION AND RESULTS}

The proposed model was applied to instances based on a domestic regional airline that carries 104 weekly flights and operates in five airports - Network 1 - and instances that represent expansions to this base network, including a new destination with a total of 164 weekly flights - Network 2 . The airport in this new destination has operation restrictions - arrival and departure time slots - that hinder the possibility of all 60 flights being selected. These networks will be tested considering several fleets with three types of aircraft commonly used by Brazilian regional airlines: ATR-42/300 (AT42, for 
50 passengers), Embraer 120 (E120, for 30 passengers), and Embraer 170 (E170, for 70 passengers) - all of them requiring a 15-minute turn-around time.

The following combinations of fleet types were selected:

- Type I: 3x AT42 (original airline fleet).

- Type II: 3x E170.

- Type III: 2x E120, 2x AT42 and 1x E170.

- Type IV: 2x AT42 and 1x E170.

As mentioned before, in order to allow the direct comparison of results with those from previous studies (Caetano \& Gualda, 2011), the demand is estimated on annual passenger totals as provided by the Brazilian Civil Aviation regulatory agency, ANAC (2007). The demand distribution for each instance can be of three different types:

- Fixed: the demand associated to each flight is fixed at 50 passengers.

- Flight: the demand is associated to each flight and is the average demand per flight, based on values provided by ANAC.

- Period: the demand between two airports associated to a period of day - morning or evening is the average demand by day period, based on values provided by ANAC.

The total demand will be different in each case: when considering fixed demand, the total will be 50 multiplied by the number of total flights. The flight and period total demands should be dependent on the origin and destination pairs served only; however, the values may be slightly different because of rounding errors.

Since there is interest in the direct comparison of results between the proposed and the usual objective functions, instances 1-I-Fixed, 2-I-Flight and 2-I-Period are exactly the same instances presented by Caetano \& Guada (2011) under number 1, 4 and 7, respectively. These instances will hereafter be referred to as "reference group".

Table 1: Optimization Results

\begin{tabular}{|c|c|c|c|c|c|c|c|c|c|c|c|}
\hline \multirow{2}{*}{ Network } & \multirow{2}{*}{ Fleet } & \multirow{2}{*}{ Demand } & \multirow{2}{*}{ BELF } & \multicolumn{2}{|c|}{ Flights } & \multicolumn{2}{|c|}{ Demand } & \multirow{2}{*}{$\begin{array}{l}\text { WTM } \\
\text { (pax.h) }\end{array}$} & \multirow{2}{*}{ LF (\%) } & \multirow{2}{*}{$\begin{array}{l}\text { TWLF } \\
\text { (\%) }\end{array}$} & \multirow{2}{*}{$\begin{array}{c}\text { MLF } \\
\text { (\%) }\end{array}$} \\
\hline & & & & Total & Selected & Total & Met & & & & \\
\hline \multirow{2}{*}{1} & \multirow{2}{*}{ I } & \multirow{2}{*}{ Fixed } & 50 & 104 & 104 & 5,200 & 5,200 & 0 & 100 & 100 & 100 \\
\hline & & & 75 & 104 & 104 & 5,200 & 5,200 & 0 & 100 & 100 & 100 \\
\hline \multirow{2}{*}{1} & \multirow{2}{*}{ II } & \multirow{2}{*}{ Fixed } & 50 & 104 & 104 & 5,200 & 5,200 & 1,537 & 71.4 & 71.4 & 71.4 \\
\hline & & & 75 & 104 & 0 & 5,200 & 0 & 3,842 & - & - & - \\
\hline \multirow{2}{*}{2} & \multirow{2}{*}{1} & \multirow{2}{*}{ Fixed } & 50 & 164 & 94 & 8,200 & 4,700 & 2,917 & 100 & 100 & 100 \\
\hline & & & 75 & 164 & 94 & 8,200 & 4,700 & 2,917 & 100 & 100 & 100 \\
\hline \multirow{2}{*}{2} & \multirow{2}{*}{1} & \multirow{2}{*}{ Flight } & 50 & 164 & 80 & 13,697 & 3,555 & 14,956 & 88.9 & 92.3 & 0 \\
\hline & & & 75 & 164 & 76 & 13,697 & 3,503 & 15,263 & 92.2 & 96.8 & 0 \\
\hline \multirow{2}{*}{2} & \multirow{2}{*}{ III } & \multirow{2}{*}{ Flight } & 50 & 164 & 127 & 13,697 & 4,993 & 13,489 & 83.8 & 88.7 & 0 \\
\hline & & & 75 & 164 & 101 & 13,697 & 4,264 & 13,664 & 94.9 & 95.5 & 66 \\
\hline \multirow{2}{*}{2} & \multirow{2}{*}{ I } & \multirow{2}{*}{ Period } & 50 & 164 & 84 & 13,680 & 3,930 & 14,502 & 93.6 & 95.6 & 88 \\
\hline & & & 75 & 164 & 84 & 13,680 & 3,930 & 14,502 & 93.6 & 95.6 & 88 \\
\hline \multirow{3}{*}{2} & \multirow{3}{*}{ IV } & \multirow{3}{*}{ Period } & 50 & 164 & 84 & 13,680 & 4,330 & 13,569 & 93.6 & 95.6 & 88 \\
\hline & & & 75 & 164 & 84 & 13,680 & 4,330 & 13,569 & 93.6 & 95.6 & 88 \\
\hline & & & 50 & 164 & 143 & 13,680 & 5,215 & 13,143 & 84.4 & 88.9 & 46.7 \\
\hline \multirow[t]{2}{*}{2} & \multirow[t]{2}{*}{ III } & \multirow[t]{2}{*}{ Period } & 60 & 164 & 110 & 13,680 & 4,862 & 13,135 & 89.9 & 92.3 & 46.7 \\
\hline & & & 75 & 164 & 109 & 13,680 & 4,745 & 13,233 & 90.6 & 93.6 & 56.7 \\
\hline
\end{tabular}

Table 1 shows the results from using different weight values for $\alpha$ and $\beta$, with at least two break-even load factors $-50 \%$ and $75 \%$. The WTM values are proportional to the objective function values and, thus, the lowest values correspond to the best solutions. All the instances were solved by integer linear programming techniques using the Gurobi Optimizer (C) software version 7 on a quad-core i7 processor running at 3.6GHz. Processing times for the instances presented in Table 1 varied from a few seconds 
(most instances) to about 4 hours (instance 2-III-Flight and 2-III-Period).

The first relevant observation is that the flight schedule obtained by processing each instance of the "reference group", when considering a BELF of $50 \%$, was practically the same obtained by Caetano \& Gualda (2011), with some flights being performed at slightly different departure times. This result implies that, for those cases, both objective functions lead to the same optimal solution and, thus, the alternative function is as good as the revenue function. On the other hand, a BELF of $50 \%$ can be considered low, suggesting that there is some room for improving the solution.

The alternative approach presented in this paper, however, allows for several experiments with the break-even load factor. Furthermore, several aircraft combinations may be tested without the need to make assumptions about fares and operational costs. One combination of specific interest is the solution for instance 2-I-Flight - part of the "reference group" - with a BELF of 75\%, when compared to the solution for a BELF of $50 \%$. When the BELF was set at 75\%, four flights were excluded from the schedule, reducing the demand met by 52 passengers, but increasing the TWLF from $92.3 \%$ to $96.8 \%$ and thus suggesting a slightly more efficient flight schedule than that obtained with the original model - while avoiding the need for additional assumptions regarding the yield management.

By analyzing the data presented in Table 1, it is possible to notice that adjusting the BELF does not always introduce significant changes in the results. This can be particularly observed in instances 1-IFixed and 2-I-Fixed. This usually means that most flights have a high load factor, suggesting that existing fleets are a very good fit for the supplied demand forecasts. This is not an unexpected result, since in those instances the demand was purposefully defined as exactly the same as each aircraft capacity.

Instance 1-II-Fixed acts as a sanity check, using a 70-passenger aircraft for flights with only 50 passengers. When imposing a BELF of 50\%, every flight is performed with an LF of $71.4 \%$. On the other hand, imposing a BELF of $75 \%$ will hinder the viability of all flights.

Instances 2-I-Flight and 2-III-Flight show how the manipulation of the BELF can improve the LF and TWLF. The reduction of the number of flights (5\% in the first case and more than $20 \%$ in the second) compared to the reduction of the number of passengers transported (just over $1 \%$ in the first case and about $15 \%$ in the second) implies that there is a better usage of the equipment, which is expressed in the higher LF and TWLF values. The lower WTM also shows that the 2-III-Flight configuration better meets the demand - which is coherent, once the demand for each flight is very diverse and fleet type III is composed of aircraft of several capacities.

The TWLF obtained is higher than the BELF required for every tested instance. This result is expected, since BELF defines a baseline and, therefore, most flights included in the schedule will have a load factor higher than BELF. There are flights with load factor below the BELF - as shown by the "minimum load factor" column, MLF, the load factor of the least occupied flight in the solution -, but they are acting as repositioning flights, in order to allow other flights with high occupation ratios to be selected. In other words, every flight with occupation below BELF implies at least a flight with occupation above BELF.

The analysis of instances 2-I-Period and 2-IV-Period shows something similar to that, but it also shows that some flights selected to be flown by ATR-42/300 do not have enough demand to its full occupancy. The exchange of one ATR-42/300 by an Embraer 170 allows transporting more passengers $(4,330$ versus 3,930$)$, but the occupation remains the same. It is possible to notice that the Embraer 170 replaced the ATR-42/300 just for flights in which the demand was higher than 70 passengers, and, for this reason, the LF and TWLF have not changed for both instances.

The instance 2-III-Period, however, shows that adding a smaller aircraft - the Embraer 120, for example - to the mix, led to a significant improvement in the number of passengers transported and in the number of flights, reducing the WTM. When adopting the BELF of 50\%, however, there is a significant load factor decrease. Also, in this configuration, one ATR-42/300 aircraft was not used. There was some improvement in LF and TWLF when BELF was increased to $60 \%$, but very low occupancy remained with a load factor of just $46.7 \%$ for some aircraft. It was verified that increasing BELF to $75 \%$ can improve LF and TLW even further, and the least occupied aircraft, in this case, had a LF of 56.7\%. With BELF of $60 \%$ 
and $75 \%$, all five aircraft are used, although the use of each of them is less frequent than in the case with a $50 \%$ BELF. The reason for a higher BELF, which can lead to an increase in the number of used aircraft, is that several repositioning, low occupation flights, are not allowed in those configurations.

It is worth mentioning that the actual configuration of the airline could not be compared to previous results because it includes some airline required flights between two specific airports - the inequality in Equation 20 must be rewritten as an equality for those flights.

The results for this network 1', which includes the required flights, is shown in Table 2. This table also presents a new fleet type V, composed of 2x Embraer 120, 2x ATR-42/300 and 1x Airbus 320 - the latest in the 156 seats configuration and requiring at least 30 minutes of turn-around time between flights.

The solution obtained for instance 1'-I-Flight - the actual airline configuration -, both with BELF of $50 \%$ and $75 \%$, was exactly the actual flight schedule performed by that airline, implying that the airline was performing the optimal schedule when considering its fleet confronted to the actual demand. On the other hand, the MLF shows that some flights are selected with a very low occupation ratio - exactly those required by the airline. These results suggest that the airline would have better results utilizing smaller aircrafts, such as Embraer 120. There is some spilled demand on some flights, which would suggest incorporating a larger aircraft, such as Embraer 170. Adding these fleets, the results are presented in the same Table 2, in the form of instance 1'-III-Flight.

Table 2: Optimization Results

\begin{tabular}{|c|c|c|c|c|c|c|c|c|c|c|c|}
\hline \multirow{2}{*}{ Network } & \multirow{2}{*}{ Fleet } & \multirow{2}{*}{ Demand } & \multirow{2}{*}{ BELF } & \multicolumn{2}{|c|}{ Flights } & \multicolumn{2}{|c|}{ Demand } & \multirow{2}{*}{$\begin{array}{l}\text { WTM } \\
\text { (pax.h) }\end{array}$} & \multirow{2}{*}{ LF (\%) } & \multirow{2}{*}{$\begin{array}{c}\text { TWLF } \\
\text { (\%) }\end{array}$} & \multirow{2}{*}{$\begin{array}{l}\text { MLF } \\
\text { (\%) }\end{array}$} \\
\hline & & & & Total & Selected & Total & Met & & & & \\
\hline \multirow{2}{*}{$1^{\prime}$} & \multirow{2}{*}{ I } & \multirow{2}{*}{ Flight } & 50 & 104 & 104 & 4,177 & 3,673 & 1,604 & 70.6 & 69.0 & 28.0 \\
\hline & & & 75 & 104 & 104 & 4,177 & 3,673 & 1,604 & 70.6 & 69.0 & 28.0 \\
\hline \multirow{2}{*}{$1^{\prime}$} & \multirow{2}{*}{ III } & \multirow{2}{*}{ Flight } & 50 & 104 & 104 & 4,177 & 3,645 & 1,023 & 80.1 & 81.0 & 44.0 \\
\hline & & & 75 & 104 & 104 & 4,177 & 3,414 & 1,032 & 84.1 & 83.3 & 44.0 \\
\hline \multirow{2}{*}{$1^{\prime}$} & \multirow{2}{*}{ V } & \multirow{2}{*}{ Flight } & 50 & 104 & 104 & 4,177 & 3,572 & 1,055 & 80.6 & 81.4 & 44.0 \\
\hline & & & 75 & 104 & 104 & 4,177 & 3,362 & 1,063 & 84.2 & 83.4 & 44.0 \\
\hline
\end{tabular}

Table 2 allows observing that the alternative fleet in 1'-III-Fleet reduces the number of total passengers, but also reduces the WTM and increases the load factor by a significant amount for both BELF values. This means that, from an operational costs standpoint - and excluding maintenance considerations -, it is convenient for this airline to operate with aircrafts of multiple sizes.

Exploring this trend even further, instance 1'-V-Flight replaces the Embraer 170 by an Airbus 320. Table 2 shows that the exchange of the Embraer 170 for the Airbus 320 reduces the number of total passengers and increases the WTM, despite marginally increasing the load factors when compared to instance 1'-III-Flight. The explanation for this result can be obtained by analysing the schedule for each aircraft: while all five aircraft units are used in instance 1'-III-Flight, only four are used in instance 1'-VFlight - two ATR-42/300 and two Embraer 120. There is not enough actual demand to justify the use of the Airbus 320 and, thus, the resulting schedule does not include any flight to be flown with this aircraft.

Note, however, that these results were associated to optimal configurations for the airline operation based on the provided data. Since it is usual that costs and revenues matrices change along the years, as well as operational rules, the targeted load factor may change over time and, thus, the adequate value for BELF cannot be considered static. Therefore, the actual airline flight schedule and the adequate BELF must be determined from adequate demand projections from current data.

\section{MODEL EXPANSIONS AND FUTURE STUDIES}

The proposed objective function does not take into account differences in performance for each aircraft type. If several fleets are suitable for a flight but differ in performance - in terms of unitary revenue -, this difference could be addressed with another set of constants $\gamma_{i j}$ in the objective function, as shown in Equation 32. 


$$
[\min ] \sum_{(i, j) \in L f}\left\{T_{i j} \cdot\left[\alpha \cdot\left(\left(\sum_{f \in F} \gamma_{i j}^{f} \cdot C^{f} \cdot x_{i j}^{f}\right)-p a_{i j}\right)+\beta \cdot\left(d_{i j}-p a_{i j}\right)\right]\right\}
$$

The constant $\gamma_{i j}$ acts as a multiplier of the potential transport moment, changing the number of passengers needed to guarantee profitability when fleet $f$ flies from $i$ to $j$. Fleets with $\gamma_{i j}$ equal to 1.0 are the efficiency reference for flight $(i, j)$. Values of $\gamma_{i j}$ greater than 1.0 mean that fleet $f$ is less efficient than the reference fleet. Values of $\gamma f_{i j}$ smaller than 1.0 mean the opposite: that fleet $f$ is more efficient than the reference fleet. The calibration of these constants is out of the scope of this article and is an interesting topic for a future study.

Moreover, the model does not take into account the differences in flight times. Even though it is possible to modify it to allow different flight times for each fleet, this variation of the model is out of the scope of this study.

Regarding the proposed objective function, future studies should evaluate the impact of using different types of aircraft - turboprop versus turbofan - to incorporate and to calibrate the $\gamma f_{i j}$ constants.

About the model as a whole, future studies may consider hubs and connections to address the demand, as well as demand recapture such as proposed by other models (LOHATEPANONT \& BARNHART, 2004), and the incorporation of long term maintenance constraints (SALAZAR-GONZÁLEZ, 2014).

Since larger instances than those presented herein, including more fleet types and airports, led to huge processing times - Gurobi was unable to reach the optimal value after running more than 48 hours -, it is suitable to develop a heuristic approach to solve the problem, as proposed by Caetano \& Gualda (2011).

\section{CONCLUSION}

This paper presented an exact model with an alternative objective function to solve the integrated flight schedule and the fleet assignment problem. The proposed objective function uses the transport momentum as a proxy to the operational costs, avoiding the use of estimated monetary parameters.

The exact model proposed was tested and validated against a previously developed model which relied on airline revenues. The schedule generated for each of the instances referred to as "reference group" was the same for both approaches, but the model with the alternative objective function readily allowed for generating an improved flight schedule without any further assumptions. This result permits to consider that the new proposed objective function can replace the revenue-based objective function, which, in practice, permits the airline planner to opt for the formulation that best fits his/her reality.

The comparison of results for instances with similar proposed flights, but considering several combinations of fleets and demand distribution along the day, allowed for a comprehensive evaluation of the results in terms of coverage, wasted transport momentum, number of passengers served, and efficiency of aircraft usage.

Since no bias was introduced in the solution by exogenously defined costs, the results may represent a clean slate, the yield management strategy can be built upon and encourage the adoption of the new objective function characteristics to model and to solve other airline optimization problems.

\section{ACKNOWLEDGEMENTS}

The authors acknowledge CNPq (Conselho Nacional de Desenvolvimento Científico e Tecnológico - National Council for Scientific and Technological Development) for a Research Productivity Fellowship (Process: 307622/2015-0) and LPT/EPUSP (Laboratório de Planejamento e Operação de Transportes da Escola Politécnica da Universidade de São Paulo - Transportation Planning and Operation Laboratory of the Polytechnic School of the University of São Paulo) for the technical support.

\section{REFERENCES}

ANAC (2007) Anuário Estatístico da Agência Nacional de Aviação Civil - 2007 - vol.I. Available at http://www.anac.gov.br/assuntos/dados-e-estatisticas/dados-do-anuario-do-transporte-aereo. Access Date: 07/2017.

Barnhart, C; Cohn, A.M; Johnson, E.L; Klabjan, D; Nemhauser, G.L. \& Vance, P.H. (2003) Airline Crew Scheduling in Handbook of Transportation Science. 2nd ed. Kluwer's International Series. DOI: 10.1007/b101877. 
Berge, M.E; Hopperstad, C.A. (1993) Demand driven dispatch: A method for dynamic aircraft capacity assignment, models and algorithms. Operations Research n. 41, p. 153-168. DOI: 10.1287/opre.41.1.153.

Caetano, D.J. \& Gualda, N.D.F. (2010). A Flight Schedule and Fleet Assignment Model. In: 12th World Conference on Transport Research, Lisboa (Portugal). Selected Procedures of the 12th WCTR (Paper ID: 02492). WCTRS, v. 1, p. 1-18.

Caetano, D.J. \& Gualda N.D.F. (2011) MAGS - An Aco-based Model to Solve the Schedule Generation and Fleet Assignment Integrated Problem. In: International Conference on Evolutionary Computation Theory and Applications (ECTA), 2011, Paris. Proceedings of the ECTA. Paris: SciTePress, p. 227-232. DOI: 10.5220/0003673502270232

Di Wang, D; Klabjan, D.; Shebalov, S. Attractiveness-Based Airline Network Models with Embedded Spill and Recapture. Journal of Airline and Airport Management, [S.I.], v. 4, n. 1, p. 1-25, jan. 2014. DOI: 10.3926/jairm.20.

Dong, Z; Chuhang, Y; Henry Lau, H.Y.K. (2016) An integrated flight scheduling and fleet assignment method based on a discrete choice model. Computers \& Industrial Engineering. v.98, p.195-210. DOI: 10.1016/j.cie.2016.05.040.

Gomes, W. P. (2014) Modelagem integrada do problema de programação de tripulantes de aeronaves. Tese (Doutorado), Departamento de Engenharia de Transportes, Escola Politécnica da Universidade de São Paulo, São Paulo, SP. DOI: 10.11606/t.3.2014.tde-25112014-143703

Gomes, W.P. \& Gualda, N.D.F. (2011) Modelagem Integrada do Problema de Programação de Tripulantes de Aeronaves. Transportes, v.19, n.1, p.23-32. DOI: 10.14295/transportes.v19i1.208.

Gomes, W.P. \& Gualda, N.D.F. (2015) Heuristics to solve the integrated airline crew assignment problem. Journal of Transport Literature, v.9, p.25-39. D0I: 10.1590/2238-1031.jtl.v9n1a5.

Gürkan, H; Güreal, S; Aktük, S. (2016) An integrated approach for airline scheduling, aircraft fleeting and routing with cruise speed control. Transportation Research Part C: Emerging Technologies. v.68, p.38-57. DOI: 10.1016/j.trc.2016.03.002.

Hane, C; Barnhart, C; Johnson, E; Marsten, R; Nemhauser, G. \& Sigismondi, G. (1995) The fleet assignment problem: Solving a large-scale integer program, Technical report, Georgia Institute of Technology. Report Series 92(4). DOI: 10.1007/BF01585938.

Klabjan, D. (2004) Large-scale models in the airline industry. In G. Desaulniers, J. Desroriers, MM Solomon, editors, Column Generation, Kluwer Academic Publishers. DOI: 10.1007/0-387-25486-2_6.

Kölker, K; Bießlichb, P; Lütjensa, K. (2016) From passenger growth to aircraft movements. Journal of Air Transport Management - Part B, v.56, p.99-106. DOI: 10.1016/j.jairtraman.2016.04.021.

Lohatepanont, M. \& Barnhart, C. (2004) Airline Schedule Planning: Integrated Models and Algorithms for Schedule Design and Fleet Assignment. Transportation Science, v.38, n.1, p.19-32. DOI: 10.1287/trsc.1030.0026.

Mayo, D. (1999) Contribuições para implementação do yield management em companhias aéreas brasileiras. Dissertação. Universidade de São Paulo. São Paulo.

Rabetanety, A; Calmet, J. \& Schoen, C. (2006) Airline Schedule Planning Integrated Flight Schedule Design and Product Line Design (Master's thesis). Universität Karlsruhe, Karlsruhe, Germany.

Salazar-González, J-J. (2014) Approaches to Solve the Fleet-Assignment, Aircraft-Routing, Crew-Pairing and Crew-Rostering Problems of a Regional Carrier. Omega, v.43, p.71-82. DOI: 10.1016/j.omega.2013.06.006.

Sherali, H.D; Bish, E.K. \& Zhu, X. (2006) Airline fleet assignment concepts, models, and algorithms. European Journal of Operational Research, v.172, p.1-30. DOI: 10.1016/j.ejor.2005.01.056.

Sherali, H.D; Bae, K.H. \& Haouari, M. (2013) A benders decomposition approach for an integrated airline schedule design and fleet assignment problem with flight retiming, schedule balance, and demand recapture. Annals of Operations Research, v.210, n.1, p.213-244. DOI: 10.1007/s10479-011-0906-3.

Swan, W.M. \& Adler, N. (2006) Aircraft Trip Cost Parameters: A Function of Stage Length and Seat Capacity. Transportation Research Part E: Logistics and Transportation Review, v.42, n.2, p.105-115. DOI: 10.1016/j.tre.2005.09.004. 